\title{
A Mechanistic Link Between Selenium and Coronavirus Disease 2019 (COVID-19)
}

\author{
Saroj Khatiwada ${ }^{1}$ (D) $\cdot$ Astha Subedi $^{2}$ \\ Accepted: 23 March 2021 / Published online: 9 April 2021 \\ (C) The Author(s), under exclusive licence to Springer Science+Business Media, LLC, part of Springer Nature 2021
}

\begin{abstract}
Purpose of Review Coronavirus disease 2019 (COVID-19) is a rapidly emerging disease caused by a highly contagious virus called severe acute respiratory syndrome coronavirus 2 (SARS-CoV-2), and this disease has affected millions of people across the world and led to hundreds of thousands of deaths worldwide. Nutrition is a key factor related to this disease, and nutritional status may determine the risk and outcomes of SARS-CoV-2 infection. Selenium is one of the major trace elements required for redox functions and has significant roles in viral infections. The purpose of this review was to examine the current evidence on the role of selenium in COVID-19. We reviewed studies on selenium and COVID-19, and other relevant studies to understand how selenium status can modify the risk of SARS-CoV-2 infection, and how selenium status might affect a person post-infection. Recent Findings We found that oxidative stress is a characteristic feature of COVID-19 disease, which is linked with the immunopathological disorder observed in individuals with severe COVID-19. Selenium plays a key role in strengthening immunity, reducing oxidative stress, preventing viral infections and supporting critical illness. Moreover, selenium deficiency is related to oxidative stress and hyperinflammation seen in critical illness, and selenium deficiency is found to be associated with the severity of COVID-19 disease.

Summary Selenium supplementation at an appropriate dose may act as supportive therapy in COVID-19. Future studies in large cohorts of COVID-19 are warranted to verify the benefits of selenium supplementation for reducing risk and severity of COVID19.
\end{abstract}

Keywords Antioxidants · Coronavirus disease (COVID-19) $\cdot$ Immunity $\cdot$ Micronutrients $\cdot$ Selenium $\cdot$ Severe acute respiratory syndrome coronavirus 2 (SARS-CoV-2)

\section{Introduction}

Selenium is an essential trace element required for the functioning of all organisms. The primary source of human body selenium is diet from plant and animal origin, which largely depends on the soil selenium content, and the bioavailability

Saroj Khatiwada

khatiwadasaroj22@gmail.com

Astha Subedi

asthasubedi22@gmail.com

1 School of Medical Sciences, UNSW Sydney, Sydney, Australia

2 Medicine ICU, Tribhuvan University Teaching Hospital, Kathmandu, Nepal of soil selenium to crops [1, 2]. Globally, selenium deficiency is thought to affect 500 million to 1 billion people, and the deficiency is widespread in some parts of China, New Zealand and Europe [3]. The common diseases resulting from its deficiency include Keshan disease and Kashin-Beck disease [2]. Selenium has an important role in maintaining redox balance in cells, and its antioxidant and anti-inflammatory activity is attributed to its role in immunity $[4 \bullet, 5]$. Therefore, selenium is of significance in viral infections, and it can play a vital role in supporting coronavirus disease 2019 (COVID-19).

COVID-19 is a rapidly emerging disease that began in December 2019 and has already affected millions of people worldwide and led to hundreds of thousands of deaths [6]. This disease is caused by severe acute respiratory syndrome coronavirus 2 (SARS-CoV-2), a highly contagious virus, which is transmitted primarily through respiratory droplets [7•]. Coronaviruses are a large family of viruses that infect humans and/or animals. The coronavirus subfamily is further 
classified into four genera: alpha, beta, gamma and delta coronaviruses. Other major coronaviruses that were responsible for human outbreaks with life-threatening infection include the Middle East respiratory syndrome coronavirus (MERS-CoV causes MERS) and severe acute respiratory syndrome coronavirus (SARS-CoV causes SARS) [8].

The uprising number of COVID-19 cases with many patients advancing to severe illness followed by strict lockdown across many countries has crippled the global economy [9]. Interestingly, the rate of COVID-19 infection and disease severity has been found to differ among countries, and many of the contributing factors for such differences remains unexplored [6]. Factors such as age, body physiological status, immunity, nutritional status, genetic factors, variation in gut and lung microbiota population, and environmental factors may be involved in determining the susceptibility to SARSCoV-2 infection and the outcomes of its infection [10-15]. Elderly people and adults with certain medical conditions are found to be at increased risk of severe illness from COVID-19 than others [16, 17]. Common medical conditions that predispose to severe illness in individuals with COVID19 include cancer, chronic kidney disease, chronic obstructive pulmonary disease, immunocompromised state, obesity, heart diseases, sickle cell disease and type 2 diabetes mellitus [17].

In this review, we briefly discuss COVID-19, including the mechanism of SARS-CoV-2 infection. We describe how oxidative stress in COVID-19 is linked with the immunopathogenic state observed in individuals with COVID-19. We overview the potential explanations for the low impact of COVID-19 in children. Following the discussion on COVID-19, we briefly discuss the relationship between nutrition and particularly micronutrients and COVID-19. After that, we talk about selenium and its metabolism in brief. Following this, we critically investigated the available information on the link between selenium and COVID-19 and discuss the critical roles of selenium in preventing viral infections, immune response, redox balance and immunopathogenesis. Finally, we discuss the impact of selenium supplementation on viral infections with reference to COVID-19, and on patients with a critical illness. In all of these discussions, we focused on how selenium can minimise oxidative stress, cytokine immunopathology and severity of the disease, and enhance immunity. The goal was to seek an answer if selenium deficiency increases the risk and severity of COVID-19 infection and if selenium supplementation can minimise such trends. We conducted a search of the major databases, PubMed and Scopus, for the keywords "coronavirus disease 2019", "COVID-19", "SARS-CoV-2" and "selenium" and included the relevant studies. All the available original articles reporting nutrient and selenium status in individuals with COVID-19 were incorporated for review. Based on the critical review of literature, selenium appears to be a promising nutrient for defending viral infections, with some potential benefits for COVID-19, and this nutrient has a potentiality to support COVID-19 management. Further studies are necessary to ascertain if selenium supplementation can reduce SARS-CoV-2 infection and severity of this disease.

\section{The COVID-19 Disease}

COVID-19 is commonly characterised by fever, dry cough and tiredness. Other symptoms may include aches and pains, nasal congestion, anosmia, sore throat and diarrhoea $[18,19]$. The clinical presentation of this disease varies among individuals, and more than $80 \%$ of the infected person can remain asymptomatic or display mild symptoms, and such cases act as a silent carrier of this disease [18]. Moreover, the SARS$\mathrm{CoV}-2$ is highly resilient in the external environment and can remain viable for up to 3 days on steel and plastic surfaces, which increases the likelihood of infecting several people from a single source [20]. Although COVID-19 is a disease of the respiratory system that particularly invades lungs which can progress to pneumonia and acute respiratory distress syndrome (ARDS), emerging studies have found that SARSCoV-2 also infects extrapulmonary tissues and organs and can lead to multiple-organ injury [21]. Extrapulmonary manifestations of this disease include thromboembolism, myocardial dysfunction and arrhythmia, acute coronary syndromes, acute kidney injury, gastrointestinal symptoms, hepatocellular injury, hyperglycaemia and ketosis, neurologic symptoms, ocular symptoms and dermatologic complications $[18,21]$.

\section{Mechanism of SARS-CoV-2 Infection}

Coronaviruses are enveloped positive-stranded RNA viruses, which contain crown-like spike proteins on their surface [7•]. The spike protein facilitates attachment of the virus to respiratory cell surface. The epithelium of the human nose, mouth and lungs has an angiotensin-converting enzyme 2 (ACE2) receptor which the virus utilises as a receptor for attachment. Once inside the cells, the virus releases its RNA and starts the replication process. The virus uses host cell machinery to make its components for multiplication, after which the newly formed virions are released from damaged cells [7•, 18]. The viral multiplication causes cell death, and new cells are invaded by the newly released virions. The mechanism of viral entry and multiplication is shown in Fig. 1. The extent of tissue damage depends on the host immunity and the ability of a virus to escape from host defences. 
Fig. 1 Mechanism of SARS$\mathrm{CoV}-2$ infection

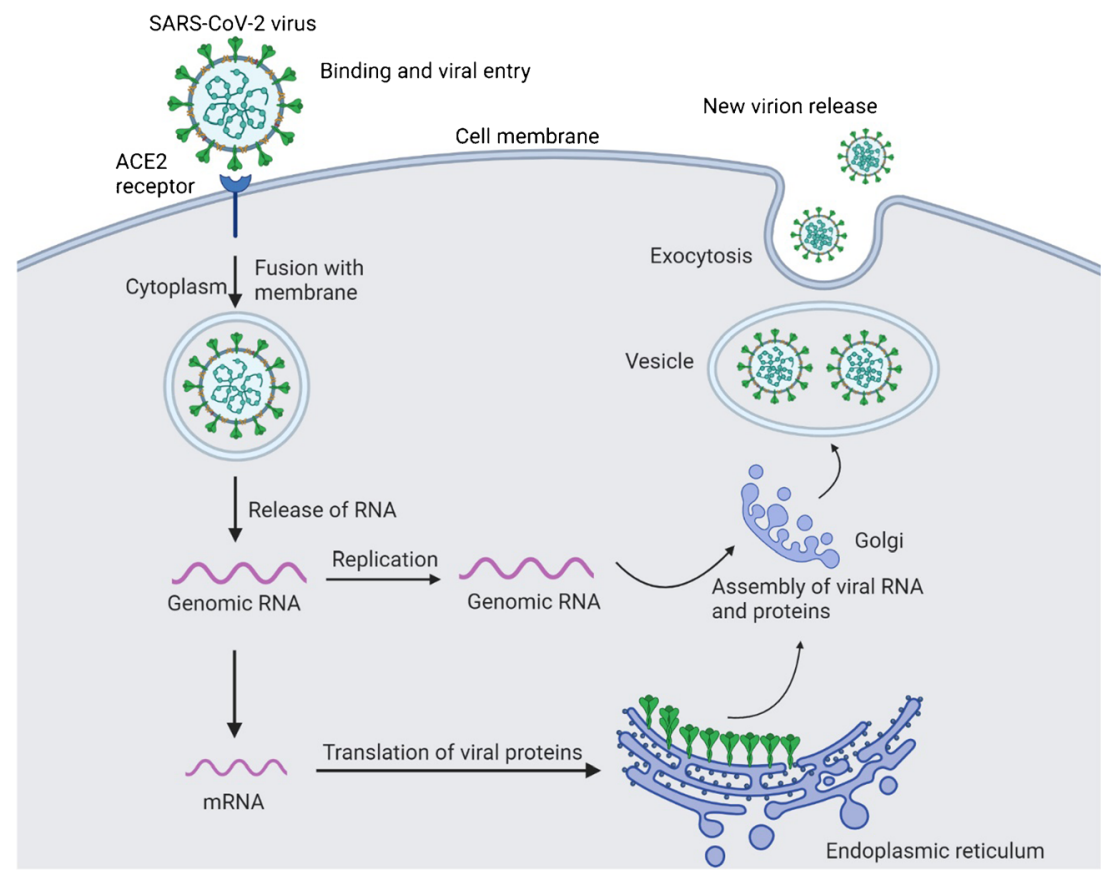

\section{Oxidative Stress in COVID-19}

Oxidative stress is a condition of imbalance between free radical generation and antioxidant defences. Overload of free radicals such as hydroxyl radical $\left(\mathrm{OH}^{*}\right)$, superoxide anion radical $\left(\mathrm{O}_{2}{ }^{-}\right)$, hydrogen peroxide $\left(\mathrm{H}_{2} \mathrm{O}_{2}\right)$ and peroxyl (ROO') is toxic because of their ability to react and damage biological molecules such as DNA, RNA, protein, carbohydrate and lipid. Excess of free radical damages cells and tissues initiating inflammation. Activation of inflammatory pathways further adds to intensifying oxidative stress [22]. While reactive oxygen species (ROS) such as superoxide is an integral component of immune defence mechanisms and cell signalling, excessive ROS production is detrimental to health.

The entry of SARS-CoV-2 virus into lung cells can initiate cellular oxidative stress because the virus utilises host cell machinery and impedes with cell-intrinsic metabolic and physiologic process. Such viral activities will induce a cellular stress response. The budding of the virion from host cells further disrupts the cell membrane and can cause cell lysis. Thus, in COVID-19, there is an imbalance in cell redox state with excessive free radicals particularly ROS production, and activation of inflammatory signalling pathways which will further evoke free radical generation causing tissue damage [23]. Hence, the markers of cellular and systemic oxidative stress are estimated to rise in individuals with COVID-19. Accordingly, the blood level of inflammatory molecules including C-reactive protein (CRP) and serum Nox2 derived peptides which contribute to oxidative stress have been found to rise in individuals with COVID-19 [19, 24, 25••].
There are opinions that the degree of oxidative stress in COVID-19 may be linked with the severity of COVID-19 disease, including the extent of tissue damage and hyperinflammation [26]. In a study, circulating levels of inflammatory markers, Nox2, high-sensitivity (hs)-CRP and Ddimer were higher in COVID-19 patients admitted to intensive care units (ICU) than non-admitted patients, and in patients with thrombotic events than those without thrombotic events. This finding, in particular, shows the prospect of inflammatory blood markers to differentiate the severity of COVID-19 disease [25••].

\section{Immunopathological Response to COVID-19}

In about $5 \%$ of individuals with COVID-19, the disease progresses into a critical illness characterised by respiratory failure requiring mechanical ventilation and ICU support, systemic sepsis and multiorgan dysfunction $[18,27]$. The lungs of such COVID-19 patients undergo pathological changes depicted as ground-glass opacity [19, 27]. Excessive generation of free radicals in the lungs leads to oxidative stress, and this is a critical factor for pulmonary tissue damage [28•]. The oxidative stress and lesions in the lungs which often evolve to ARDS are believed to be one of the most important causes of immunopathologic response, and this is one of the most common causes of death in COVID-19 [29].

While a protective immune response is initiated after all COVID-19 infections, in some patients, the immune response is pathologic and life-threatening, which is termed as cytokine 
storm [30]. Cytokine storm is an acute hyperinflammatory response characterised by an increased level of multiple cytokines including interleukin (IL)-6, IL-1b and tumour necrosis factor-alpha (TNF- $\alpha$ ) which result in endothelial dysfunction, vascular damage and metabolic dysregulation, all of which contribute to damage of multiple organs $[14,30]$. The magnitude of pathologic immune response correlates with factors such as the extent of tissue damage, multiorgan failure and host characteristics [31]. Taking into account cytokine storm and concurrent oxidative stress in severe COVID-19 cases, diminishing the production of cytokines and oxidative stress appears to have a positive impact in critically ill COVID-19 patients.

\section{Low Susceptibility and Severity of COVID-19 in Children}

COVID-19 is largely found to be mild in the children (except infants) with fatality rate being very low as compared to adults [32-34]. This finding conflicts with the previous concept that children have an immature immune system and have a higher proneness to microbial infections with subsequent development of severe symptoms. In fact, children seem to have a stronger resistance to SARS-CoV-2 infection and have a good prognosis of this disease. Multiple factors contribute to the superior defence against SARS-CoV-2 infection, and low disease severity in children $[33,35]$. One of the main factors is efficient humoral immunity leading to antibody formation against virus spike specific protein and memory B cells [36]. Many respiratory viral infections are quite common in children, and therefore, the prevalent immune response against previous viral infections may act to protect from SARSCoV-2 infection. Children have a lesser expression of ACE2 receptor in the lungs than adults, and therefore virus has less chance to invade their lungs [35]. Once infected, children develop less intense immunopathological reactions which are probably due to an immature immune system not trained to cause hyperinflammation, and therefore, there is a less chance of developing ARDS [37]. Other supporting factors include better repair power (of damaged respiratory tissues), and low occurrence of comorbid conditions.

Several questions remain unanswered as to why COVID19 is less infective in children than compared to adults who have a robust immune system. Some argue that children have a high metabolic rate and a strong antioxidant system that can well tolerate the oxidative stress induced by a viral infection. In contrast, elderly have a low metabolic rate coupled with a weak antioxidant system which is unable to bear viral infection-induced oxidative stress and inflammation [26]. This highlights the importance of strong antioxidant capacity and emphasises the necessity of boosting antioxidant status in vulnerable people. Accompanying this, another critical factor implicated for the augmenting pathogenicity of a virus is host nutritional status. Host nutritional status determines cellular and physiological conditions that are linked to the emergence of pathogenic viruses with genetic modifications [38].

\section{The Link Between Nutrition and COVID-19}

There has been a steady rise in the rate of chronic diseases and a fall in infectious diseases across the world in the past decades [39]. COVID-19 is the first infectious disease of pandemic scale in the twenty-first century in the context of a high rate of chronic diseases. This increases the odds of having chronic diseases in COVID-19 cases, and therefore, the possible influence of chronic diseases on increasing COVID-19 infection, disease severity and mortality should not be underestimated. A systematic review and meta-analysis found that underlying chronic diseases such as hypertension, diabetes, cardiovascular disease and respiratory disease are significantly more common in critical/mortal patients compared to the non-critical COVID-19 patients [17].

Nutrition has a critical role in determining health and disease. A healthy diet and adequate exercise decrease the risk of several chronic diseases. Consumption of energy-dense diets and inadequate exercise results in weight gain and obesity, which can lead to diseases such as diabetes, metabolic syndrome, cardiovascular disease and chronic kidney diseases [40]. To date, there is no direct evidence if consumption of high-energy diet around SARS-CoV-2 exposure can increase the risk of COVID19 infection and disease severity. Still, it can be speculated that consumption of unhealthy diets rich in energy but poor in micronutrients over the period can increase risk and severity of COVID-19 disease. Conversely, low-energy diet and inadequate micronutrient consumption called undernutrition reduce immunity, and therefore predisposes to COVID-19 infection [41]. Thus, optimal nutrition is essential for developing competent immunity to fight against viral infections, including COVID-19 [42, 43].

Individuals with COVID-19, particularly those with severe disease and admitted to ICU, are highly vulnerable to nutritional deficiencies. The plasma albumin concentration, a marker of nutritional status, was found to be lower in nonsurvivors of COVID-19 as compared to survivors [44]. A study in Wuhan reported that a large proportion $(61 \%)$ of critically ill COVID-19 patients had high nutritional risk, and patients with high nutritional risk at ICU admission demonstrated significantly higher mortality of ICU 28-day. Such patients exhibited significantly higher incidences of ARDS, acute myocardial injury, secondary infection and shock [45]. Overall, maintaining optimum nutrition is essential in individuals with COVID-19. 


\section{Role of Micronutrients in Viral Infection Including SARS-CoV-2 Infection}

Micronutrients are the substances required in small amount in diet and essential for biochemical reactions. Even though they do not directly provide energy, they participate in metabolic processes that release energy, support immune functions and acts as antioxidants. The major micronutrients involved in protecting against viral infections include vitamins $\mathrm{A}, \mathrm{C}, \mathrm{D}$, E, B6 and B12, folate, iron, zinc, copper, selenium and magnesium [46]. Some of these micronutrients (vitamin A, C and D) help to maintain intact epithelium by promoting epithelial growth and differentiation, which will prevent viral entry. Others act as potent antioxidants inside membrane lipid (vitamin E) and cytoplasm (vitamin C, vitamin A, copper, zinc, selenium) protecting membrane and organelles, and facilitate innate and adaptive immunity [46, 47]. Deficiency of one of these micronutrients can decline immune function and increase susceptibility to viral infections and slow down the recovery after infection $[43,48]$.

Currently, one of the key things to understand is whether micronutrient status can determine the propensity to COVID19 infection and severity of the disease. There are also concerns about the high rate of suboptimal micronutrient deficiencies in communities which remain unidentified, and such unrecognised deficiencies can have an important role in the current pandemic. In a small study in South Korea, vitamin D and selenium deficiency were seen in $76 \%$ and $42 \%$ of COVID-19 patients, with higher deficiency rate in patients with severe disease. In the same study, pyridoxine and folate deficiency were seen in $6.1 \%$, and $4.0 \%$ respectively [49॰]. Another study in Switzerland found lower plasma vitamin D in COVID-19 patients than healthy controls [50•]. Perhaps based on the emerging evidence about micronutrient requirement in COVID-19, a consensus statement from Shanghai medical panel was released which advised the use of a high dose of intravenous ascorbate for the treatment of ARDS, along with other supportive therapies, including vitamin $\mathrm{D}$ and zinc [51]. One recent meta-analysis showed that vitamin C supplementation in hospitalised patients could reduce the length of mechanical ventilation required by $18 \%$ and the length of ICU stay by $8 \%$ [52]. Currently, several clinical trials on vitamin $\mathrm{D}$, vitamin $\mathrm{C}$, zinc and selenium supplementation are underway for their benefits in COVID-19 disease. In this review, we only highlight the role of selenium, and other similarly acting micronutrients are out of the scope of this review.

\section{Selenium Chemistry and Metabolism}

The atomic number and weight of selenium are 34 and 78.971 respectively, and the daily dietary recommended intake is 55 $\mu \mathrm{g} /$ day in adults [53]. Selenium is a component of several enzymes and proteins. In the human body, selenium occurs mainly as a part of amino acid, selenocysteine, which is found in at least 25 selenocysteine-containing proteins called selenoproteins $[4 \cdot, 53]$. The major selenoproteins in human include five selenium-containing glutathione peroxidases (GPx1-4 and GPx6), three thioredoxin reductases (TrxR1-3), three iodothyronine deiodinases, one methionine sulfoxide reductase B1, selenoprotein $\mathrm{P}, \mathrm{H}, \mathrm{K}, \mathrm{M}, \mathrm{N}, \mathrm{R}, \mathrm{S}$, and $\mathrm{W}, 15 \mathrm{kD}$ selenoprotein, mitochondrial capsular selenoprotein and selenophosphate synthetase-2 [53-55].

The major dietary sources of selenium are Brazil nuts, seeds, mushrooms, fish, selenium yeast, seafood, beef and poultry [3]. In diet, most of the selenium occurs in the form of selenomethionine, selenocysteine, selenite and selenate, all of which have excellent bioavailability, and absorbed well without regulation [56]. In the intestine, selenomethionine is absorbed via intestinal methionine transporters. Once, inside the cell, selenomethionine directly participates in protein synthesis or get metabolised to release selenocysteine which can be further catabolised to selenide. Selenocysteine uptake occurs mainly through dibasic amino acid transporters in the intestine, where they can be converted to selenides and enter selenium pool. Inorganic forms of selenium, selenite and selenate, are absorbed through a simple diffusion process $[2,56]$. The liver is the principal organ supplying selenium to other tissues by secreting selenoprotein $\mathrm{P}$ into systemic circulation. The peripheral cells then take selenoprotein $\mathrm{P}$ through receptor-mediated endocytosis, where selenium is utilised or recycled [2]. At higher selenium intake, it can be toxic and the excess body selenium gets excreted through urine and faeces.

\section{Link Between Selenium and COVID-19}

Selenium deficiency seems to be common in COVID-19, as shown by a study in South Korea, where a high rate of selenium deficiency based on the measurement of blood selenium was found [49•]. In one of the first study of its kind, selenium deficiency was associated with higher mortality in COVID-19 patients [57]. In hospitalised patients, deficiency of nutrients is very common, and therefore in the severe form of COVID-19, selenium deficiency can be quite common. The inadequate selenium intake persists in a large proportion of world population across several countries, and this can have a considerable impact on COVID-19 infection and outcomes. Such notion is supported by a finding from China, where selenium status was associated with cure rates of COVID-19 [58 ${ }^{\bullet}$. Moreover, infectious viral diseases such as HIV, influenza and Ebola are more likely to evolve and spread in areas where soils are deficient in selenium [59]. This is because selenium deficiency promotes viral mutations, replication and the emergence of a more pathogenic form of RNA viruses. 
The high risk of oxidative damage of the lungs in COVID19 is partly counteracted by selenium and selenoproteins in the lungs. Further evidence on selenium status in COVID-19 patients, including those with and without disease severity, is expected to emerge rapidly as many researchers are investigating if selenium supplementation can lower the impact of this disease. Some of the principal functions of selenium in COVID-19 disease include preventing viral infection, lowering viral pathogenicity, boosting immunity, lowering oxidative stress, inflammation and pathogenesis of the disease. We discuss these functions in detail below.

\section{Role of Selenium in Viral Infections Including SARS-CoV-2}

The first evidence for the role of selenium in viral infections came from Keshan disease, where Coxsackie virus and low selenium intake were the aetiology factors [60]. For a virus to infect the host cell, it must find an appropriate receptor to bind. In the case of SARS-CoV-2 virus, the primary receptor is the ACE2 receptor. Following the binding, the virus is taken inside the host cell via endocytosis, where viral multiplication occurs. Selenium and selenoproteins indirectly affect those viral activities by contributing to several defensive mechanisms. Selenium supports structural integrity and intactness of respiratory epithelial barrier, which will lower viral entry to respiratory cells. In a similar type of RNA virus, influenza, selenium nanoparticles functionalised with antiviral agent amantadine were shown to inhibit the binding of H1N1 virus with the host cell by suppressing neuraminidase activity [61]. Therefore, selenium has the potential to modify the binding affinity of a virus with human receptor and decrease the infection rate.

Emerging evidence on selenium status in viral diseases reveals the link between selenium and viral infections. A study in China showed that selenium deficiency increases hantavirus infection in both rodents and humans [62]. Furthermore, under selenium-deficient conditions, viruses are found to mutate rapidly to become more virulent, and upon selenium sufficiency, the mutagenesis of virus decreases followed by dumping of virulence $[60,63,64]$. Thus, selenium plays a vital role in reducing viral pathogenicity and infection rate.

\section{Selenium Is a Potent Immunonutrient Against SARS-CoV-2}

Immunity is a body defence against infections and includes innate and adaptive immunity, both of which comprise multiple components. The first line of innate defence against virus includes nonspecific defence mechanism such as mechanical and chemical barriers which are made up of intact epithelial cells on the skin and mucosal surfaces that will not allow easy viral access to the body. On the mucosal surfaces of the respiratory tract, the epithelial cells are bathed by fluids and mucous, which minimises direct attachment of viruses. Furthermore, the fluid is composed of defensive peptides and enzymes that can kill common invading agents [65]. Selenium enhances the synthesis of defensive proteins and antioxidant enzymes present on the mucosal surface [66].

Selenium is required for the activities of phagocytic cells. Phagocytic cells are a major component of the innate immunity system. Insufficient selenium intake reduces phagocytic selenium level, which can reduce oxidative burst as seen in the neutrophils from selenium-deficient rats [67]. In a swine study, the neutrophils from selenium-deficient animals exhibited decreased phagocytic activity as compared to control animals [68]. In mice peritoneal macrophage, selenium deficiency-induced excess oxygen free radicals, decreased phagocytic capacity, weakened antioxidant capacity and increased the expression of inflammation markers including inducible nitric oxide synthase (iNOS), IL-1 $\beta$, IL-12, IL-10, prostaglandin E synthase (PTGE) and nuclear factor kappa beta (NF-kB) [69]. Thus, it appears that under seleniumdeficient conditions, cells have reduced ability to phagocytose and eliminate the invading virus.

In individuals with COVID-19, total lymphocytes, CD4+ T cells, CD8+ T cells, B cells and natural killer (NK) cells are found to decrease, and severe cases had a lower number of these cells than mild cases [70]. Selenium status may influence some of these parameters, such as B cell function and T cell differentiation and function [67]. Selenium intake is found to modulate free thiol levels and $\mathrm{T}$ cell activation. In mice, selenium deficiency was found to reduce $\mathrm{T}$ cell proliferation while selenium supplementation increased $\mathrm{T}$ cell activation and differentiation [71]. In a healthy human study, seleniumsupplemented group produced high titre of antibody against diphtheria inoculation than compared to non-supplemented group [72]. It is understood that during selenium deficiency, not all the tissues are equivalently supplied with low selenium stores, and immune cells are one of the first tissues to face a rapid decline which will result in less selenoprotein synthesis. This will increase the risk of being infected by SARS-CoV-2 in selenium-deficient people with adverse outcomes.

\section{Role of Selenium in Redox Homeostasis}

Selenoproteins have a crucial role in maintaining redox balance virtually in all tissues. COVID-19 is characterised by increased oxidative stress; therefore, selenium seems beneficial. Excessive production of ROS and other free radicals contributes to lung injury with a propensity to develop critical illness in COVID-19. In selenium-deficient conditions, blood and tissue oxidative stress is found to increase in animals [68, 
73]. Among the H1N1-infected children of 2009-2010 pandemic, an increase in C-reactive protein and lipid peroxidation levels and a marked decrease in both plasma and erythrocyte selenium levels and GPx1, GPx3 and TrxR activities were seen [74]. Conversely, selenium supplementation has been shown to reduce oxidative stress and support the management of critically ill patients in ICU [75-77•].

Broadly, selenoproteins with antioxidant functions fall under one of the two antioxidant systems: the thioredoxin system which consists of thioredoxin, thioredoxin peroxidase and TrxRs and the thiol redox system which consists of glutathione (GSH), GSH reductase, glutaredoxin and GPxs [55]. These selenoproteins are located at different locations within cells such as organelles, cytoplasm and in the extracellular space. The most prominent GPxs with antioxidant function include GPx1, GPx2, GPx3 and GPx4, whereas the most important TrxR are TrxR1, TrxR2 and TrxR3. Other prominent antioxidant selenoproteins are methionine sulfoxide reductase B1, selenoprotein P and selenoprotein W [76•]. The GPx enzymes use glutathione as a cofactor, which is reduced back by glutathione reductase, and GPx catalyse reduction of oxidants like hydrogen peroxide and various other organic hydroperoxides such as phospholipids and cholesterol hydroperoxides [2]. The TrxR catalyse conversion of oxidised thioredoxin to reduced form by using NADPH as a cofactor molecule [55]. Overall, the principal function of selenoproteins is to protect the cell from oxidative stress and balance redox state.

Some evidence suggests that selenium species have redox activity, and this activity has the potential to react with SARSCoV-2 main protease $\mathrm{M}^{\text {pro }}\left[7^{\bullet}\right]$. Zhang et al. put forward that low molecular selenium compounds such as methyl selenol, dimethyl selenides and selenium nanoparticles, which are mostly achieved in human body by high intake of selenium, can modify cysteine 145 residues of SARS-CoV-2 M protein. This modification can stop viral replication by truncating the viral life cycle [76 ${ }^{\bullet}$. In a related RNA virus, influenza, selenium nanoparticles functionalised in amantadine reduced the generation of ROS in kidney cell line while they were infected with influenza virus [61].

Administration of substances that can reduce oxidative stress seems quite promising in individuals with COVID-19. To this end, apart from selenium, several other compounds with antioxidant function are being tested currently. A report from a phase I trial among critically ill COVID-19 patients showed that administration of methylene blue dye, along with antioxidants: vitamin $\mathrm{C}$ and $\mathrm{N}$-acetyl cysteine, significantly improves the markers of oxidative stress [78]. In a recent review, several actions of $\mathrm{N}$-acetyl cysteine during viral infection were discussed. It suggested that $\mathrm{N}$-acetyl cysteine has inherent antioxidant activity, and it helps to minimise viral multiplication and lowers the severity of influenza virus disease [79]. Moreover, a molecular dynamics study predicted that $\mathrm{N}$-acetyl cysteine could reduce disulphide bonds on spike protein of SARS-CoV-2 and ACE2 receptor to thiol groups, thereby hindering the binding between ACE2 receptor and SARS-CoV-2 virus [80]. If proven successful by in vivo studies, this proposed mechanism can attenuate COVID-19 infections. In a case study of two COVID-19 patients developing pneumonia, high-dose oral and/or intravenous glutathione improved dyspnoea within an hour of treatment with further improvement of respiratory symptoms over repeated use [81]. Glutathione is a major antioxidant molecule in the lungs, and therefore, promoting its synthesis seems quite beneficial in COVID-19 patients [79]. Boosting endogenous glutathione production by using the supplement can be developed as a key therapeutic approach for reducing COVID-19-related complications. Overall, several types of antioxidant treatment appear to be useful in individuals with COVID-19.

\section{Relationship Between Selenium and Immunopathogenesis of COVID-19}

Lung tissue damage can initiate a pathological immune response, termed as cytokine storm, in individuals with COVID-19. This state is characterised by increased production of free radicals, inflammation and exaggerated release of cytokines, all of which provokes inflammation and organ damage [30]. To date, there is no direct evidence from COVID-19 patients if selenium status mediates cytokine storm; however, evidence from other studies in animal and human supports the role of selenium in the immunopathogenesis of COVID-19 [82-84]. Furthermore, low lung selenium, if existing, may impede with its repair and healing process.

In immunopathological condition, there is a risk of selenium deficiency, and accordingly, the blood selenium is likely to drop than normal patients. Conversely, in seleniumdeficient conditions, blood inflammatory cytokine levels are shown to rise. In a study among elderly people, people with a higher level of inflammatory cytokine, IL-6, had higher odds of having selenium deficiency, and serum selenium was inversely associated with IL-6 [82]. In chickens, selenium deficiency reduced the expression of selenoprotein genes in the spleen and increased the inflammatory cytokine levels [83]. In human bronchial epithelial cell lines infected with influenza virus, selenium-deficient cells produced more amount of IL-6 than selenium sufficient cells [84]. Further evidence showed that polymorphism $(105 \mathrm{G} / \mathrm{A})$ in one of the important selenoproteins, selenoprotein $\mathrm{S}$, is strongly linked with the circulating level of inflammatory cytokines, IL-1 $\beta$, IL- 6 and $\mathrm{TNF}-\alpha[85]$. This study further suggests the contribution of selenoprotein genetics to the inflammatory response.

Sepsis is one of the common immunopathological conditions characterised by cytokine storm, and severe inflammation and oxidative stress are initiated commonly by antigens 
released from microorganisms after infection. Selenium deficiency is quite common in sepsis patients, and the degree of deficiency is often related to the severity of the disease [67, 86]. In a human study, low plasma selenium concentrations were found in critically ill patients, with further deterioration of plasma selenium concentrations in patients with sepsis than those without infection. As compared to the patient without sepsis, sepsis patients had increased oxidative stress as indicated by lower plasma GPx3 but higher lipid hydroperoxides and myeloperoxidase, and a higher level of inflammatory markers, CRP and soluble urokinase-type plasminogen activator receptor [87].

Evidence from animal and human studies suggests that optimal selenium status or administration of selenium can prevent excessive cytokine production. In critically ill patients with ARDS, intravenous selenium supplementation replenished blood selenium level, the antioxidant capacity of lungs, and lung functions. Moreover, the serum concentration of IL-1 and IL-6 correlated inversely with serum selenium [77•]. In a mice study, the oxidative stress and inflammation induced by applying toxic levels of aluminium were moderated by selenium supplementation [88]. In view of these findings, it appears that SARS-CoV-2 infection-induced immunopathogenesis can be influenced by selenium status, and therefore, maintaining optimal selenium intake is vital. This notion is supported by recent findings where selenium status was associated with mortality and cure rate of COVID19 patients $[57,58 \cdot]$.

\section{Selenium Supplementation in COVID-19}

Low selenium status is quite common among critically ill patients [86, 87]. Similarly, among COVID-19 patients, low selenium status is more common in those with severe disease $[57,58 \bullet]$. Selenium supplementation boosts immune response and lowers oxidative stress and inflammation and virulence behaviour of viruses $[53,60,75]$. In addition, there is a prospect that selenium and selenium-containing compounds supplementation can lower the ability of SARS-CoV-2 virus to infect humans [76•].

Selenium supplement has shown dramatic benefits in the immune functions of the elderly. Selenium supplement increased total $\mathrm{T}$ cells, particularly CD4+ T cell and percentage increase in NK cells followed by an increase in NK cell cytotoxicity [89]. In mice infected with influenza virus, selenium supplementation decreased mice mortality in a dosedependent manner, and this was partly through an increase in TNF- $\alpha$ and interferon (IFN)- $\gamma$ in selenium-supplemented mice [90]. In chicken, dietary selenium supplementation enhanced antiviral immune response against low pathogenic avian influenza virus strain subtype H9N2 as demonstrated by higher transcription of antiviral response genes: IFN- $\alpha, \beta$ and $\gamma$ in the tissues as compared to controls. This antiviral response was related to the decreased viral shedding from the animals [91]. In the hepatoma cell models, sodium selenite was found to suppress transcription and replication of hepatitis $B$ virus in a dose-dependent manner [92].

There are several other benefits of selenium and its compounds. An organoselenium compound, ebselen, has received attention recently because of its ability to inhibit main protease of SARS-CoV-2, its antiviral activity and role as glutathione peroxidase and peroxiredoxin mimetic [93•]. In mice studies, selenium was found to provoke a stronger immune response when used as an adjuvant in addition to ginseng stem-leaf saponins for the pseudorabies vaccine [94, 95]. Some hypothesise that a compound of selenium, selenite used in supplementation, reacts with the sulphhydryl group of viral protein disulphide isomerase and convert to inactive disulphide form, thereby preventing viral entry to cells [96]. The prospect of using such selenium compounds is worthful because they add additional benefits aside from supporting selenoprotein synthesis.

\section{Selenium Supplementation in Critically III COVID-19 Patients}

Preliminary evidence has shown selenium to be very important in critically ill COVID-19 patients [57, 58•]. Moreover, the degree of selenium deficiency may be linked with mortality risk in critically ill patients. In a clinical trial, high doses of selenium were found to reduce mortality from septic shock [97]. Respiratory problems are the critical problems in critically ill COVID-19 patients [18]. Lungs selenoproteins can help to mitigate such problems by reducing the impact of viral invasion and tissue injury by acting as antioxidants and modulating several immune response pathways $[4 \cdot, 98]$. In mice infected with porcine circovirus, selenium supplementation decreased the lung lesions and reduced markers of inflammation [99]. This finding suggests that selenium therapy may be able to decrease lung lesions and reduce inflammation.

A number of studies have tested if selenium supplement can lower the death rate and outcome of pneumonia in ventilated patients and there are mixed results with some studies showing positive or no benefits $[77 \bullet, 100 \bullet-102 \bullet \bullet]$. Selenium supplementation in mechanically ventilated patients following sepsis was found to reduce the occurrence of ventilatorassociated pneumonia in a RCT [100•]. In another clinical trial, parenteral selenium supplementation reduced the incidence of ventilator-associated pneumonia and severity of illness in critically ill patients with systemic inflammatory response syndrome $[101 \bullet \cdot$. A high dose of selenium in critically ill patients improved antioxidant status measured as plasma GPx3 but did not improve the incidence of ventilator- 
associated pneumonia after treatment [102••]. Overall, selenium supplementation seems to be promising, and therefore, maintaining adequate selenium intake, particularly among COVID-19 patients in the ICU, should be encouraged. While supplementing selenium, it is also important to adhere to the appropriate dose, and the blood levels need to be monitored carefully to minimise potential toxicity.

\section{Conclusions}

COVID-19 is a rapidly emerging disease that can lead to critical illness with serious respiratory distress and cytokine storm. Increased oxidative stress and excessive production of inflammatory cytokines is a critical component of severe COVID-19 disease. Therefore, maintaining optimal micronutrient intake, particularly those with antioxidant activities, is essential to counteract developing oxidative stress and inflammation, and to boost the immune system. Selenium, an essential trace element, strengthens the immune system, lowers viral infection and reduces oxidative stress and inflammation. Because of those functions, selenium is an essential nutrient in COVID-19 disease. Furthermore, selenium is essential for critically ill patients, and its deficiency is often associated with severity and mortality rate of critical illness. Moreover, a link between selenium deficiency and severity of COVID-19 disease suggests the importance of this nutrient in COVID-19. The results of selenium supplementation in critically ill patients are promising; therefore, selenium supplementation may be an additional strategy to manage COVID-19 disease. Future studies in large cohorts are necessary to validate the benefits of selenium supplementation in COVID-19 disease.

Acknowledgements The figure was made using BioRender.com.

Availability of Data and Material Not applicable.

Author Contribution SK and AS generalised the concept. SK and AS conducted the literature search, analysed relevant literature and drafted the manuscript. All authors reviewed the manuscript. All authors read and approved the final version of the manuscript.

\section{Declarations}

Human and Animal Rights and Informed Consent This article does not contain any studies with human or animal subjects performed by any of the authors.

\section{Consent for Publication Not applicable.}

Competing Interests None.

\section{References}

Papers of particular interest, published recently, have been highlighted as:

- Of importance

- Of major importance

1. Kieliszek M. Selenium-fascinating microelement, properties and sources in food. Molecules. 2019;24(7):1298.

2. Fairweather-Tait SJ, Bao Y, Broadley MR, Collings R, Ford D, Hesketh JE, et al. Selenium in human health and disease. Antioxid Redox Signal. 2011;14(7):1337-83.

3. Shreenath AP, Ameer MA, Dooley J. Selenium deficiency. StatPearls. Treasure Island (FL): StatPearls Publishing. Copyright (c) 2020, StatPearls Publishing LLC; 2020.

4. Guillin OM, Vindry C, Ohlmann T, Chavatte L. Selenium, selenoproteins and viral infection. Nutrients. 2019;11(9):2101. This recent review highlights the role of selenium in viral infections.

5. Hoffmann PR, Berry MJ. The influence of selenium on immune responses. Mol Nutr Food Res. 2008;52(11):1273-80.

6. CSSE JHU. Wuhan coronavirus (2019-nCoV) global cases. 2020.

7. Shereen MA, Khan S, Kazmi A, Bashir N, Siddique R. COVID19 infection: origin, transmission, and characteristics of human coronaviruses. J Adv Res. 2020;24:91-8 This review discusses the current evidence on COVID-19 virus and its characteristics.

8. Gorbalenya AE, Baker SC, Baric RS, de Groot RJ, Drosten C, Gulyaeva AA, et al. The species Severe acute respiratory syndrome-related coronavirus: classifying $2019-\mathrm{nCoV}$ and naming it SARS-CoV-2. Nat Microbiol. 2020;5(4):536-44.

9. Nicola M, Alsafi Z, Sohrabi C, Kerwan A, Al-Jabir A, Iosifidis C, et al. The socio-economic implications of the coronavirus pandemic (COVID-19): a review. Int J Surg. 2020;78:185-93.

10. Lakshmi Priyadarsini S, Suresh M. Factors influencing the epidemiological characteristics of pandemic COVID 19: a TISM approach. Int J Healthc Manag. 2020;13(2):89-98.

11. Hou Y, Zhao J, Martin W, Kallianpur A, Chung MK, Jehi L, et al. New insights into genetic susceptibility of COVID-19: an ACE2 and TMPRSS2 polymorphism analysis. BMC Med. 2020;18(1): 216.

12.• Calder PC. Nutrition, immunity and COVID-19. BMJ Nutr Prev Health. 2020:bmjnph-2020-000085 This review highlights on the immune response and the role of common nutrients in COVID-19 disease and its pathogenesis.

13. Briguglio M, Pregliasco FE, Lombardi G, Perazzo P, Banfi G. The malnutritional status of the host as a virulence factor for new coronavirus SARS-CoV-2. Front Med. 2020;7:146. This opinion article overviews the potential association between malnutrition and pathogenesis of COVID-19 disease.

14. Khatiwada S, Subedi A. Lung microbiome and coronavirus disease 2019 (COVID-19): possible link and implications. Hum Microb J. 2020;17:100073.

15. Zuo T, Zhang F, Lui GCY, Yeoh YK, Li AYL, Zhan H, et al. Alterations in gut microbiota of patients with COVID-19 during time of hospitalization. Gastroenterology. 2020;159(3):94455.e8.

16. Davies NG, Klepac P, Liu Y, Prem K, Jit M, Pearson CAB, et al. Age-dependent effects in the transmission and control of COVID19 epidemics. Nat Med. 2020;26(8):1205-11.

17. Zheng Z, Peng F, Xu B, Zhao J, Liu H, Peng J, et al. Risk factors of critical \& mortal COVID-19 cases: a systematic literature review and meta-analysis. J Infect. 2020;81(2):e16-25. 
18. Cascella M, Rajnik M, Cuomo A, Dulebohn SC, Di Napoli R. Features, evaluation and treatment coronavirus (COVID-19). StatPearls. Treasure Island (FL): StatPearls Publishing. Copyright (C) 2020, StatPearls Publishing LLC; 2020.

19. Guan W-j, Ni Z-y, Hu Y, Liang W-h, Ou C-q, He J-x, et al. Clinical characteristics of coronavirus disease 2019 in China. N Engl J Med 2020;382(18):1708-1720.

20. van Doremalen N, Bushmaker T, Morris DH, Holbrook MG, Gamble A, Williamson BN, et al. Aerosol and surface stability of SARS-CoV-2 as compared with SARS-CoV-1. N Engl J Med. 2020;382(16):1564-7.

21. Gupta A, Madhavan MV, Sehgal K, Nair N, Mahajan S, Sehrawat TS, et al. Extrapulmonary manifestations of COVID-19. Nat Med. 2020;26(7):1017-32.

22. Liguori I, Russo G, Curcio F, Bulli G, Aran L, Della-Morte D, et al. Oxidative stress, aging, and diseases. Clin Interv Aging. 2018;13:757-72.

23. Checconi P, De Angelis M, Marcocci ME, Fraternale A, Magnani M, Palamara AT, et al. Redox-modulating agents in the treatment of viral infections. Int J Mol Sci. 2020;21(11):4084.

24. Jing Liang J, Liu J, Chen Y, Ye B, Li N, Wang X, et al. Characteristics of laboratory findings of COVID-19 patients with comorbid diabetes mellitus. Diabetes Res Clin Pract. 2020;167: 108351.

25.• Violi F, Oliva A, Cangemi R, Ceccarelli G, Pignatelli P, Carnevale R, et al. Nox2 activation in Covid-19. Redox Biol. 2020;36: 101655 This clinical study found an association between Nox-2-derived oxidative stress and COVID-19 disease, and the level of Nox-2-derived oxidative stress was associated with severity of disease.

26. Keles ES. Mild SARS-CoV-2 infections in children might be based on evolutionary biology and linked with host reactive oxidative stress and antioxidant capabilities. New Microbes New Infect. 2020;36:100723.

27. Lovato A, de Filippis C. Clinical presentation of COVID-19: a systematic review focusing on upper airway symptoms. Ear Nose Throat J. 2020;99(9):569-76.

28. Schönrich G, Raftery MJ, Samstag Y. Devilishly radical NETwork in COVID-19: oxidative stress, neutrophil extracellular traps (NETs), and T cell suppression. Adv Biol Regul. 2020;77: 100741 This review highlights how oxidative stress generated in COVID-19 disease is linked with disease severity.

29. Coperchini F, Chiovato L, Croce L, Magri F, Rotondi M. The cytokine storm in COVID-19: an overview of the involvement of the chemokine/chemokine-receptor system. Cytokine Growth Factor Rev. 2020;53:25-32.

30. Bhaskar S, Sinha A, Banach M, Mittoo S, Weissert R, Kass JS, et al. Cytokine Storm in COVID-19-Immunopathological mechanisms, clinical considerations, and therapeutic approaches: the REPROGRAM consortium position paper. Front Immunol. 2020;11:1648.

31. Ragab D, Salah Eldin H, Taeimah M, Khattab R, Salem R. The COVID-19 cytokine storm; what we know so far. Front Immunol. 2020;11:1446.

32. Götzinger F, Santiago-García B, Noguera-Julián A, Lanaspa M, Lancella L, Calò Carducci FI, et al. COVID-19 in children and adolescents in Europe: a multinational, multicentre cohort study. Lancet Child Adolesc Health. 2020;4:653-61.

33. Kloc M, Ghobrial RM, Kuchar E, Lewicki S, Kubiak JZ. Development of child immunity in the context of COVID-19 pandemic. Clin Immunol. 2020;217:108510.

34. Yasuhara J, Kuno T, Takagi H, Sumitomo N. Clinical characteristics of COVID-19 in children: a systematic review. Pediatr Pulmonol. 2020;55(10):2565-75.

35. Lingappan K, Karmouty-Quintana H, Davies J, Akkanti B, Harting MT. Understanding the age divide in COVID-19: why are children overwhelmingly spared? Am J Physiol Lung Cell Mol Physiol. 2020;319(1):L39-144.

36. Zhang Y, Xu J, Jia R, Yi C, Gu W, Liu P, et al. Protective humoral immunity in SARS-CoV-2 infected pediatric patients. Cell Mol Immunol. 2020;17(7):768-70.

37. Jia R, Wang X, Liu P, Liang X, Ge Y, Tian H, et al. Mild cytokine elevation, moderate CD4(+) T cell response and abundant antibody production in children with COVID-19. Virol Sin. 2020;35(6):734-43.

38. Beck MA, Handy J, Levander OA. Host nutritional status: the neglected virulence factor. Trends Microbiol. 2004;12(9):417-23.

39. Hajat C, Stein E. The global burden of multiple chronic conditions: a narrative review. Prev Med Rep. 2018;12:284-93.

40. CDC. About Chronic Diseases 2020 cited 2020. Available from: https://www.cdc.gov/chronicdisease/about/index.htm. Accessed 28 Oct 2020.

41. Bourke CD, Berkley JA, Prendergast AJ. Immune dysfunction as a cause and consequence of malnutrition. Trends Immunol. 2016;37(6):386-98.

42. Jayawardena R, Sooriyaarachchi P, Chourdakis M, Jeewandara C, Ranasinghe P. Enhancing immunity in viral infections, with special emphasis on COVID-19: A review. Diabetes Metab Syndr. 2020;14(4):367-82.

43. Zabetakis I, Lordan R, Norton C, Tsoupras A. COVID-19: The inflammation link and the role of nutrition in potential mitigation. Nutrients. 2020;12(5):1466.

44. Zhou F, Yu T, Du R, Fan G, Liu Y, Liu Z, et al. Clinical course and risk factors for mortality of adult inpatients with COVID-19 in Wuhan, China: a retrospective cohort study. Lancet. 2020;395(10229):1054-62.

45. Zhang P, He Z, Yu G, Peng D, Feng Y, Ling J, et al. The modified NUTRIC score can be used for nutritional risk assessment as well as prognosis prediction in critically ill COVID-19 patients. Clin Nutr. 2021;40(2):534-541.

46. Gasmi A, Tippairote T, Mujawdiya PK, Peana M, Menzel A, Dadar M, et al. Micronutrients as immunomodulatory tools for COVID-19 management. Clin Immunol. 2020;220:108545.

47. Elmadfa I, Meyer AL. The role of the status of selected micronutrients in shaping the immune function. Endocr Metab Immune Disord Drug Targets. 2019;19(8):1100-15.

48. Wintergerst ES, Maggini S, Hornig DH. Contribution of selected vitamins and trace elements to immune function. Ann Nutr Metab. 2007;51(4):301-23.

49. Im JH, Je YS, Baek J, Chung MH, Kwon HY, Lee JS. Nutritional status of patients with coronavirus disease 2019 (COVID-19). Int J Infect Dis. 2020;100:390-93. This study in COVID-19 patients found vitamin $\mathrm{D}$ and selenium deficiency in the majority of patients.

50. D'Avolio A, Avataneo V, Manca A, Cusato J, De Nicolò A, Lucchini R, et al. 25-Hydroxyvitamin D concentrations are lower in patients with positive PCR for SARS-CoV-2. Nutrients. 2020;12(5):1359. This study reported significantly lower level of vitamin D in SARS-CoV-2 PCR-positive patients as compared to PCR negative patients.

51. Cheng RZ, Kogan M, Davis D. Ascorbate as prophylaxis and therapy for COVID-19-update from Shanghai and U.S. medical institutions. Glob Adv Health Med. 2020;9:2164956120934768.

52. Hemilä H, Chalker E. Vitamin C can shorten the length of stay in the ICU: a meta-analysis. Nutrients. 2019;11(4):708.

53. Mehdi Y, Hornick J-L, Istasse L, Dufrasne I. Selenium in the environment, metabolism and involvement in body functions. Molecules (Basel, Switzerland). 2013;18(3):3292-311.

54. Zhang Y, Roh YJ, Han S-J, Park I, Lee HM, Ok YS, et al. Role of selenoproteins in redox regulation of signaling and the antioxidant system: a review. Antioxidants (Basel). 2020;9(5):383. 
55. Labunskyy VM, Hatfield DL, Gladyshev VN. Selenoproteins: molecular pathways and physiological roles. Physiol Rev. 2014;94(3):739-77.

56. Burk RF, Hill KE. Regulation of selenium metabolism and transport. Annu Rev Nutr. 2015;35:109-34.

57. Moghaddam A, Heller RA, Sun Q, Seelig J, Cherkezov A, Seibert $\mathrm{L}$, et al. Selenium deficiency is associated with mortality risk from COVID-19. Nutrients. 2020;12(7):2098. This study found an association between COVID-19 mortality risk and selenium status.

58. Zhang J, Taylor EW, Bennett K, Saad R, Rayman MP. Association between regional selenium status and reported outcome of COVID-19 cases in China. Am J Clin Nutr. 2020;111(6): 1297-9 This study in China reports an asociation between selenium status in cities and cure rates from COVID-19 disease.

59. Harthill M. Review: micronutrient selenium deficiency influences evolution of some viral infectious diseases. Biol Trace Elem Res. 2011;143(3):1325-36.

60. Steinbrenner H, Al-Quraishy S, Dkhil MA, Wunderlich F, Sies H. Dietary selenium in adjuvant therapy of viral and bacterial infections. Adv Nutr. 2015;6(1):73-82.

61. Li Y, Lin Z, Gong G, Guo M, Xu T, Wang C, et al. Inhibition of H1N1 influenza virus-induced apoptosis by selenium nanoparticles functionalized with arbidol through ROS-mediated signaling pathways. J Mater Chem B. 2019;7(27):4252-62.

62. Fang LQ, Goeijenbier M, Zuo SQ, Wang LP, Liang S, Klein SL, et al. The association between hantavirus infection and selenium deficiency in mainland China. Viruses. 2015;7(1):333-51.

63. Beck MA, Nelson HK, Shi Q, Van Dael P, Schiffrin EJ, Blum S, et al. Selenium deficiency increases the pathology of an influenza virus infection. FASEB J. 2001;15(8):1481-3.

64. Beck MA, Kolbeck PC, Rohr LH, Shi Q, Morris VC, Levander OA. Benign human enterovirus becomes virulent in seleniumdeficient mice. J Med Virol. 1994;43(2):166-70.

65. Marshall JS, Warrington R, Watson W, Kim HL. An introduction to immunology and immunopathology. Allergy, Asthma Clin Immunol. 2018;14(Suppl 2):49.

66. Shi X, Wang W, Zheng S, Zhang Q, Xu S. Selenomethionine relieves inflammation in the chicken trachea caused by LPS though inhibiting the NF-KB pathway. Biol Trace Elem Res. 2020;194(2):525-35.

67. Huang Z, Rose AH, Hoffmann PR. The role of selenium in inflammation and immunity: from molecular mechanisms to therapeutic opportunities. Antioxid Redox Signal. 2012;16(7):705-43.

68. Yang T, Zhao Z, Liu T, Zhang Z, Wang P, Xu S, et al. Oxidative stress induced by Se-deficient high-energy diet implicates neutrophil dysfunction via $\mathrm{Nrf} 2$ pathway suppression in swine. Oncotarget. 2017;8(8):13428-39.

69. Xu J, Gong Y, Sun Y, Cai J, Liu Q, Bao J, et al. Impact of selenium deficiency on inflammation, oxidative stress, and phagocytosis in mouse macrophages. Biol Trace Elem Res. 2020;194(1):237-43.

70. Wang F, Nie J, Wang H, Zhao Q, Xiong Y, Deng L, et al. Characteristics of peripheral lymphocyte subset alteration in COVID-19 pneumonia. J Infect Dis. 2020;221(11):1762-9.

71. Hoffmann FW, Hashimoto AC, Shafer LA, Dow S, Berry MJ, Hoffmann PR. Dietary selenium modulates activation and differentiation of CD4+ T cells in mice through a mechanism involving cellular free thiols. J Nutr. 2010;140(6):1155-61.

72. Hawkes WC, Kelley DS, Taylor PC. The effects of dietary selenium on the immune system in healthy men. Biol Trace Elem Res. 2001;81(3):189-213.

73. Li S, Zhao Q, Zhang K, Sun W, Jia X, Yang Y, et al. Se deficiency induces renal pathological changes by regulating selenoprotein expression, disrupting redox balance, and activating inflammation. Metallomics. 2020;12:1576-84.

74. Erkekoğlu P, Așçı A, Ceyhan M, Kızılgün M, Schweizer U, Atas $\mathrm{C}$, et al. Selenium levels, selenoenzyme activities and oxidant/ antioxidant parameters in H1N1-infected children. Turk J Pediatr. 2013;55(3):271-82.

75. Fakhrolmobasheri M, Nasr-Esfahany Z, Khanahmad H, Zeinalian M. Selenium supplementation can relieve the clinical complications of COVID-19 and other similar viral infections. Int J Vitam Nutr Res. 2020:1-3.

76. Zhang J, Saad R, Taylor EW, Rayman MP. Selenium and selenoproteins in viral infection with potential relevance to COVID-19. Redox Biol. 2020;37:101715. This review highlights the importance of selenium in COVID-19 pathogenesis.

77. Mahmoodpoor A, Hamishehkar H, Shadvar K, Ostadi Z, Sanaie $\mathrm{S}$, Saghaleini SH, et al. The effect of intravenous selenium on oxidative stress in critically ill patients with acute respiratory distress syndrome. Immunol Investig. 2019;48(2):147-59 This clinical trial found that selenium supplementation can enhance antioxidant capacity of lungs and lower inflammation.

78. Alamdari DH, Moghaddam AB, Amini S, Keramati MR, Zarmehri AM, Alamdari AH, et al. Application of methylene blue -vitamin $\mathrm{C}-\mathrm{N}$-acetyl cysteine for treatment of critically ill COVID-19 patients, report of a phase-I clinical trial. Eur J Pharmacol. 2020;885:173494.

79. De Flora S, Balansky R, La Maestra S. Rationale for the use of Nacetylcysteine in both prevention and adjuvant therapy of COVID-19. FASEB J. 2020;34:13185-93.

80. Hati S, Bhattacharyya S. Impact of thiol-disulfide balance on the binding of Covid-19 spike protein with angiotensin-converting enzyme 2 receptor. ACS Omega. 2020;5(26):16292-8.

81. Horowitz RI, Freeman PR, Bruzzese J. Efficacy of glutathione therapy in relieving dyspnea associated with COVID-19 pneumonia: a report of 2 cases. Respir Med Case Rep. 2020;30:101063.

82. Tseng CK, Ho CT, Hsu HS, Lin CH, Li CI, Li TC, et al. Selenium is inversely associated with interleukin-6 in the elderly. J Nutr Health Aging. 2013;17(3):280-4.

83. Khoso PA, Zhang Y, Yin H, Teng X, Li S. Selenium deficiency affects immune function by influencing selenoprotein and cytokine expression in chicken spleen. Biol Trace Elem Res. 2019;187(2):506-16.

84. Jaspers I, Zhang W, Brighton LE, Carson JL, Styblo M, Beck MA. Selenium deficiency alters epithelial cell morphology and responses to influenza. Free Radic Biol Med. 2007;42(12):1826-37.

85. Curran JE, Jowett JBM, Elliott KS, Gao Y, Gluschenko K, Wang $\mathrm{J}$, et al. Genetic variation in selenoprotein $\mathrm{S}$ influences inflammatory response. Nat Genet. 2005;37(11):1234-41.

86. Belsky JB, Wira CR, Vinitha J, Sather JE, Lee PJ. A review of micronutrients in sepsis: the role of thiamine, 1-carnitine, vitamin C, selenium and vitamin D. Nutr Res Rev. 2018;31(2):281-90.

87. Mertens K, Lowes DA, Webster NR, Talib J, Hall L, Davies MJ, et al. Low zinc and selenium concentrations in sepsis are associated with oxidative damage and inflammation. $\mathrm{Br} \mathrm{J}$ Anaesth. 2015;114(6):990-9.

88. Viezeliene D, Beekhof P, Gremmer E, Rodovicius H, Sadauskiene I, Jansen E, et al. Selective induction of IL- 6 by aluminuminduced oxidative stress can be prevented by selenium. J Trace Elem Med Biol. 2013;27(3):226-9.

89. Wood SM, Beckham C, Yosioka A, Darban H, Watson RR. $\beta$ Carotene and selenium supplementation enhances immune response in aged humans. Integr Med. 2000;2(2):85-92.

90. Yu L, Sun L, Nan Y, Zhu LY. Protection from H1N1 influenza virus infections in mice by supplementation with selenium: a comparison with selenium-deficient mice. Biol Trace Elem Res. 2011;141(1-3):254-61. 
91. Shojadoost B, Kulkarni RR, Yitbarek A, Laursen A, TahaAbdelaziz K, Negash Alkie T, et al. Dietary selenium supplementation enhances antiviral immunity in chickens challenged with low pathogenic avian influenza virus subtype H9N2. Vet Immunol Immunopathol. 2019;207:62-8.

92. Cheng Z, Zhi X, Sun G, Guo W, Huang Y, Sun W, et al. Sodium selenite suppresses hepatitis B virus transcription and replication in human hepatoma cell lines. J Med Virol. 2016;88(4):653-63.

93. Sies H, Parnham MJ. Potential therapeutic use of ebselen for COVID-19 and other respiratory viral infections. Free Radic Biol Med. 2020;156:107-12 This article discusses the potential benefits of organoselenium drug, ebselen for improving COVID-19 disease.

94. Maqbool B, Wang Y, Cui X, He S, Guan R, Wang S, et al. Ginseng stem-leaf saponins in combination with selenium enhance immune responses to an attenuated pseudorabies virus vaccine. Microbiol Immunol. 2019;63(7):269-79.

95. Wang Y, Cui X, Yuan L, Maqbool B, Xu W, He S, et al. A Solution with ginseng saponins and selenium as vaccine diluent to increase Th1/Th2 immune responses in mice. J Immunol Res. 2020;2020:2714257.

96. Kieliszek M, Lipinski B. Selenium supplementation in the prevention of coronavirus infections (COVID-19). Med Hypotheses. 2020;143:109878.

97. Forceville X. Effects of high doses of selenium, as sodium selenite, in septic shock patients a placebo-controlled, randomized, double-blind, multi-center phase II study-selenium and sepsis. J Trace Elem Med Biol. 2007;21(Suppl 1):62-5.

98. Bermano G, Méplan C, Mercer DK, Hesketh JE. Selenium and viral infection: are there lessons for COVID-19? Br J Nutr.
2021;125(6):618-27. This review discusses the potential influence of selenium status on COVID-19 disease.

99. Liu G, Yang G, Guan G, Zhang Y, Ren W, Yin J, et al. Effect of dietary selenium yeast supplementation on porcine circovirus type 2 (PCV2) infections in mice. PLoS One. 2015;10(2):e0115833.

100. Chelkeba L, Ahmadi A, Abdollahi M, Najafi A, Ghadimi MH, Mosaed R, et al. The effect of parenteral selenium on outcomes of mechanically ventilated patients following sepsis: a prospective randomized clinical trial. Ann Intensive Care. 2015;5(1):29 Selenium supplementation improved activity of antioxidant enzyme, glutathione peroxidase in septic patients.

101.• Manzanares W, Biestro A, Torre MH, Galusso F, Facchin G, Hardy G. High-dose selenium reduces ventilator-associated pneumonia and illness severity in critically ill patients with systemic inflammation. Intensive Care Med. 2011;37(7):1120-7 This clinical trial found improvement in illness severity of critically ill patients Further reduction in incidence of hospital acquired pneumonia was observed after selenium supplementation.

102.• Mahmoodpoor A, Hamishehkar H, Sanaie S, Behruzizad N, Iranpour A, Koleini E, et al. Antioxidant reserve of the lungs and ventilator-associated pneumonia: a clinical trial of high dose selenium in critically ill patients. J Crit Care. 2018;44:357-62 This clinical trial tested the effect of a high dose of selenium in critically ill patients on the incidence of ventilatorassociated pneumonia. Selenium supplement increased the antioxidant capacity but not the incidence of ventilatorassociated pneumonia.

Publisher's Note Springer Nature remains neutral with regard to jurisdictional claims in published maps and institutional affiliations. 